\title{
Viera y Clavijo: Historiador ilustrado del Atlántico
}

\section{Viera y Clavijo: Enlightenment Historian Atlantic}

\author{
Juan Manuel Santana Pérez \\ jmsantana@dch.ulpgc.es \\ Catedrático de Historia Moderna \\ Universidad de Las Palmas de Gran Canaria-Espanha \\ ULPGC - c/ Pérez del Toro, 1 \\ 35003 - Las Palmas de Gran Canaria \\ España
}

\begin{abstract}
Resumen
Analizamos la producción historiográfica de Viera y Clavijo, ilustrado canario que tuvo una obra destacada en el conjunto de España. Hemos hecho una labor hermenéutica de su obra, así como la incorporación de informaciones que están en archivos canarios. Creemos que hace falta profundizar en su filosofía de la historia. La obra historiográfica de Viera y Clavijo fue la primera visión de conjunto de la Historia de Canarias en concordancia con las ideas ilustradas, especialmente influenciado por historiadores franceses, que sin ser la más vanguardista en Europa, supuso un enorme paso adelante en el pensamiento canario de la segunda mitad del siglo XVIII. Al tiempo que destaca la atlanticidad de Canarias, también destaca las características conferidas por la insularidad. La geografía fue un aspecto que Viera y Clavijo estimaba que dificultaba la propagación de las ideas religiosas e ilustradas. La separación insular, con una orografía accidentada, hacía que determinados lugares fueran inaccesibles. La identidad canaria es deudora de la obra de Viera y Clavijo, muchos de sus mitos e imaginarios arrancan de su Historia y continúa en esos cánones de la ilustración canaria dieciochesca.
\end{abstract}

\section{Palabras claves}

Ilustración; Historiografía; Identidad.

\begin{abstract}
We analyze the historiographical production of Viera y Clavijo, enlightenment canary that had an outstanding work in the whole of Spain. We have made a hermeneutic work with this work, as well as the incorporation of information that Canary files have. There is a need to deepen their philosophy of history. Historiographical work of Viera y Clavijo was the first overview of the history of the Canary Islands in accordance with the enlightened ideas, especially influenced by French historians, without being the most avant-garde in Europe, was a huge step forward in the Canary thought of the second half of the eighteenth century. While stressing the Atlanticism of Canarias, also it highlights the characteristics conferred by insularity. Geography was an aspect that Viera estimated that hindered the spread of religious and enlightened ideas. The island apart with a rugged terrain, made certain places inaccessible. The Canarian identity is indebted to the work of Viera y Clavijo, many of their myths and imaginary tear from his history and continues in those canons of eighteenth-century Canarian illustration.
\end{abstract}

Keywords

Enlightenment; Historiography; Identity.

Recibido el: 4/8/2016

Aceptado el: 6/4/2017 
En la Corona española durante el absolutismo borbónico, las artes y el saber lograron un reconocimiento oficial con la fundación de las Academias reales como la Real Academia de la Historia en 1738. Además, en tiempos de Carlos III se organizaron los Archivos Históricos de Indias y de la Corona de Aragón.

Las Islas Canarias fueron un área semiperiférica del Imperio hispano, pero vivió avances culturales fruto de una élite ilustrada encargada de fomentar e impulsar el aparato productivo, movido por un interés bien entendido que la llevaba a preocuparse de la situación económica del campesinado, así como a emplear nuevos métodos para intervenir con consejos y órdenes en las obsoletas estructuras. En estas islas hubo una importante actividad intelectual que se movía en el marco del horizonte de ideas ilustradas nada despreciables y comparables con otras experiencias dentro de la Corona española, de hecho, se avanzó en los conceptos agronómicos y se intentó llevarlas a la práctica, aunque con poco éxito entre otras razones por la falta de medios $y$, sobre todo, por la verticalidad con que pretendían aplicarlas. En este contexto, la recuperación de la historia formaba parte de ese gran plan de conocimiento de los pueblos y fomento de las actividades culturales. En Canarias el personaje más destacado de este movimiento ilustrado fue José de Viera y Clavijo.

A pesar de que es bien conocida la biografía de José de Viera y Clavijo, creemos preciso señalar algunos datos básicos para entender sus concepciones filosóficas y, en consecuencia, historiográfica. Nació el 28 de diciembre de 1731 en el Realejo de Arriba, en la isla de Tenerife, su padre era alcalde de la localidad, ${ }^{1}$ y murió en la ciudad de Las Palmas el 21 de febrero de 1813. Pronto se mudó con su familia al entonces Puerto de La Orotava, hoy Puerto de la Cruz, allí recibió su primera formación; se trataba de una localidad portuaria abierta a la llegada de productos, personas y costumbres europeas. Estudió teología y filosofía escolástica en el convento de Santo Domingo de La Orotava. En 1753 es subdiácono y, más tarde, accedió a las órdenes mayores para conseguir el presbiteriado en Gran Canaria. En 1757 pasó a residir con sus padres a la ciudad más importante de Canarias del momento, La Laguna, allí entró en contacto con los ilustrados canarios, incluso formó parte de la Tertulia de Nava. En 1770, bajo el reinado de Carlos III, en el momento del auge de la Ilustración española, se estableció Madrid, en la casa del marqués de Santa Cruz, quien marcará sus pasos en la Corte, fue ayo de su hijo primogénito. Desde allí recorrió buena parte de Castilla y Andalucía. La experiencia y el conocimiento de los viajes por Europa constituyeron un eje crucial en la formación de las elites ilustradas canarias (GALVÁN 2013, p. 23-36). En 1777 viaja por Francia y Flandes acompañando al joven Marqués del Santa Cruz, y en 1781, acompañando al propio Marqués de Santa Cruz padre por Italia, Austria y Alemania. Sobre los viajes de Viera tenemos un artículo que analiza de forma impecable lo que le aportó y condicionó en su obra esas experiencias (GALVÁN 1996, p. 655-668). Ese año permanece en Madrid y es nombrado por el Rey arcediano de Fuerteventura, importante

\footnotetext{
${ }_{1}^{1}$ Tenemos la partida de bautismo en una hoja de papel sellado con fecha de 5 de enero de 1732 en Archivo del Museo Canario-Las Palmas de Gran Canaria (A.M.C.), Colección de Documentos de Agustín Millares Torres, Tomo VIII, Legajo 4, s/fl.
} 
cargo eclesiástico, pero aun retrasó el retorno a las Islas dos años, es decir, que en 1783 ya está instalado en su puesto catedralicio de Canarias hasta su muerte, en la isla de Gran Canaria. En su vida fue polifacético, como gran parte de los intelectuales ilustrados, historiador, poeta, autor de una novela, eclesiástico, traductor, docente, educador, orador sacro, naturalista y periodista.

Los años de la madurez de Viera supondrán para el Archipiélago el primer brote de una nueva concepción en todos los ámbitos del pensamiento.

La Ilustración canaria estuvo apuntalada firmemente desde el principio por ciertos sectores eclesiásticos que, a pesar de parecer contestatarios para su época, se metieron de lleno en la tarea por modernizar y actualizar las estructuras sociales, económicas y culturales del Archipiélago.

El pensamiento ilustrado en Canarias llegará por medio de libros extranjeros que entraban por vía marítima, por donde penetraron las ideas, tanto impresas, como en las mentes de liberales y heterodoxos que arribaron a nuestros puertos en este periodo.

Será una Ilustración que impacte en los círculos aristocráticos y terratenientes, la tónica general en toda la Corona, sin embargo, habrá una diferencia destacable en la norma, ya que el pueblo llano de las Islas va a tomar contacto con el fenómeno, aunque solamente en instancias superficiales.

\section{Publicación de la Historia de Viera y Clavijo}

Casi todos los historiadores canarios dedicados a indagar en el pasado del Antiguo Régimen han escrito muchas páginas sobre este autor, de hecho, no hay libro que trate sobre las Islas Canarias entre los siglos XVI y XVIII que no tenga alguna referencia a Viera, siempre encontraremos alguna cita pertinente al respecto, incluso en la historia de la historiografía española del siglo XVIII debería aparecer reseñado. Creemos que su obra está a la altura de la Historia Literaria de España de los hermanos Mohedano (1766-1791) y de la Historia crítica de España y de la cultura española de J. F. Masdeu (1783-1805).

La monumental obra de Viera y Clavijo continúa siendo de obligada consulta para cualquier investigación histórica de Canarias con anterioridad al siglo XIX, además de algunos poemas con eminente contenido histórico. Su magna obra historiográfica apareció con el largo título: Noticias de la historia general de las Islas Canarias. Contienen la descripción geográfica de todas. Una idea del origen, carácter, usos y costumbres de sus antiguos habitantes: De los descubrimientos y conquistas que sobre ellas hicieron los Europeos: De su Gobierno Eclesiástico, Político y Militar: Del establecimiento, y sucesión de su primera Nobleza: De sus Varones ilustres por dignidades, empleos, armas, letras, y santidad: De sus fábricas, producciones naturales, y comercio; con los principales sucesos de los últimos siglos; ${ }^{2}$ este tipo de títulos no eran infrecuentes en la época, al contrario.

\footnotetext{
2 Hay un ejemplar original de los cuatro tomos en Archivo de la Real Sociedad Económica de Amigos del País de Tenerife (A.R.S.E.A.P.TFE), Fondo Rodríguez Moure, Sig: 22/86. También un borrador anotado y con dibujos del autor, con fecha de 1763, Sig: 20/7. Existe una edición facsímil publicada por el Gobierno de Canarias en 2004. Tenemos unos apuntes manuscritos del autor sobre este libro en A.M.C., Colección de Documentos de Agustín Millares Torres, Tomo VIII, Legajo 11, 8 fls.
} 
El libro fue publicado en cuatro tomos, impresos en Madrid, donde Viera se trasladó a vivir en 1770, tengamos en cuenta que en ese momento Canarias únicamente contaba con una imprenta establecida en Santa Cruz de Tenerife instalada en 1751 que era muy deficiente porque había sido formada con unos tipos viejos y gastados procedentes de Sevilla (LAFORET 1991, p. 19-20). Los cuatro tomos salieron respectivamente en 1772, 1773, 1776 y 1783 (CEBRIÁN 1996, p. 209-220), sacó 1.000 ejemplares de cada tomo por 35.000 reales en la imprenta de Blas Román, aunque sabemos que la había terminado de escribir muchos años antes de su publicación; el primer libro lo acabó de redactar en 1763 y en 1766 los seis siguientes.

Estructurado en 19 libros, hace un repaso completo de la Historia de Canarias. Dado que fueron apareciendo a lo largo de once años, pudo ir incluyendo nuevas informaciones en los largos prólogos que acompañaron a cada tomo, que en el caso del volumen tercero le ocupó 17 páginas. También en medio del texto podemos apreciar algunas rectificaciones con respecto a afirmaciones anteriormente publicadas, de hecho, a medida que fue editando los tomos posteriores trató de perfeccionarlos y en sus años de residencia en Madrid tuvo la oportunidad de contrastar determinadas informaciones.

Aunque es la obra más valorada de Viera y Clavijo, sin embargo, este libro no tuvo una buena acogida en su tiempo, no sabemos por qué; el propio autor se quejaba: "He publicado una obra que pocos compran, nadie lee y que muchos critican... este diluvio universal de críticas, murmuraciones y bravatas". No obstante, otros coetáneos suyos afirmaron que había diferentes opiniones, pero no dejaron de señalar los diversos ataques. ${ }^{3}$ A. Humbolt utilizó la Historia de Viera para preparar la escala que hizo en Tenerife en 1799, esto le confirió a la obra cierta relevancia europea.

Las cuentas que hizo el historiador fueron detalladas, minuciosas, revelaban el método con que siempre trabajó, característica de su personalidad ordenada. Por el análisis de esas cuentas sabemos que no anduvo muy sobrado de dinero con esta publicación ${ }^{4}$. En el segundo volumen, el autor da la noticia que el Cabildo de Tenerife había acordado darle cien ducados de ayuda para sufragar cada uno de los cuatro tomos, el acuerdo fue tomado en tres sesiones, pero nunca recibió los cuatrocientos ducados (BLANCO 1950, p. XXIV-XXV).

Según Juan Régulo (1981, p. 90), esta obra ha servido de arranque a toda la historiografía posterior del Archipiélago, sin haber sido superada por una similar visión, en conjunto, de la historia de Canarias. Quizás hoy en día es una afirmación algo exagerada.

\section{El Atlántico}

Podemos considerarlo historiador atlántico, aunque todavía de forma embrionaria, de hecho, desde el primer libro, nuestro autor asevera la africanidad de Canarias: "Estas islas pertenecen a África", de este modo comienza el primer

\footnotetext{
${ }^{3}$ A.M.C. Archivo Viera, Caja 3, sin/fol.

${ }^{4}$ A.R.S.E.A.P.TFE, Fondo Rodríguez Moure, Sig: 10/390, Manuscrito. Están editadas las cuentas que muestran esa contabilidad (ROMEU 1981, p. 122-141)
} 
capítulo del Libro Primero, así como su interés en referirlas como porciones de la antigua Atlántida. Llamar la atención a una evidencia, es decir, que Canarias se halla en África era situarla en el Atlántico, y salir del mediterráneocentrismo dominante desde inicios de la Edad Moderna (WULFF 2003), además, al ubicarla en su punto geográfico ponía en la palestra la lejanía de la Península Ibérica y con ello que al Archipiélago le afectaba su proximidad continental y su proyección hacia América, con notoria diferencia con respecto a las otras regiones de España y, esto había condicionado su sociedad. Viera afirma que los guanches procedían de "linaje de héroes atlánticos".

Se maneja entre la africanidad geográfica y la americanidad emocional, característica que ha sobrevivido en la cultura canaria. Nilo Palenzuela (1981, p. 33) ha señalado la voluntad universalista y mitopoética de Viera dentro de su mirada insular. En su Historia se reconoce que los canarios hablaban una lengua africana, aunque los hace descendientes de una mítica y heroica civilización atlántica. Fajardo $(2009$, p. 100, 110) señala con acierto que la obra se centra en el carácter atlántico de la población insular, como originaria y autóctona, unido a que la Dedicatoria, inédita en su tiempo, a Carlos III, escribe literalmente "desde el seno del Mar Atlántico".

Al tiempo que destaca la atlanticidad de Canarias, también destaca las características conferidas por la insularidad. La geografía fue un aspecto que Viera estimaba que dificultaba la propagación de las ideas religiosas e ilustradas. La separación insular, con una orografía accidentada, barrancos, precipicios, montañas, caminos impracticables, hacía que determinados lugares fueran inaccesibles, quedando por tanto fuera de los esfuerzos pastorales.

El análisis de las "tablas y materias" de los cuatro tomos es muy indicativo de su concepción de la Historia, muestra detalladamente lo que nos vamos a encontrar en el contenido.

Tras la reafirmación de la africanidad geográfica que hemos señalado, pasa a describir el espacio, la posible formación territorial, sin renunciar a encajarlo en los esquemas bíblicos, y las primeras noticias conocidas en el mundo clásico del Archipiélago con una explicación de los topónimos e introduce en un capítulo final el tema mítico de la isla de San Borondón, que aparecía y desaparecía, hoy sabemos que se debe a un fenómeno óptico en determinadas circunstancias.

En este mismo libro dedica los capítulos del 9 al 13 a demostrar que las Islas Canarias son los restos del antiguo continente de la Atlántida. En la creencia en el continente de la Atlántida hay un intento de desacralización acorde con el proceso de secularización y regalismo que se vive en España a lo largo del siglo XVIII. En la Biblia debía estar contenida una explicación para las poblaciones de todo el planeta. Viera recoge que en Canarias, siguiendo el pensamiento judeocristiano que creía que todo partía del pueblo judío, aseveraban la idea bíblica que todo el poblamiento del mundo procedía del Cercano Oriente, donde habría estado el paraíso terrenal, se pensaba que los aborígenes isleños procedían de los descendientes de Noé, concretamente de sus hijos Cam y Jafet ya que Fut, un hijo del primero había ido hacia África, además, en Éxodo capítulo 36 versículo 36 se refiera a un personaje Ilamado Gomer, hijo del citado Jafet, y en 
algún momento fue asimilado con el nombre original de la isla de La Gomera. Las Sagradas Escrituras no podía quedar al margen de la crítica general. La Historia de Viera abandona las interpretaciones providencialistas, no podía estar al margen de las orientaciones críticorracionalistas y, de este modo, se superaba la visión historiográfica agustiniana, en la que la Providencia dominaba las intenciones de los seres humanos y todo en la Historia se dirigía a la salvación o condenación de un mundo futuro. La crítica es una actividad misma de la razón que trata de obtener por medio del pensamiento racional, conocimientos exactos. Con estas afirmaciones, acorde con la cultura ilustrada, se distancia del judeocentrismo que insinuaba que todo el mundo se había formado en torno a la nación judía. Algo similar hizo el marqués de Valdeflores en Los Anales de la nación española, que escribió en 1759, donde elimina una filiación directa que conecte la historia bíblica con los orígenes de España (ÁLVAREZ 1996, p. 160).

No obstante, el primer ilustrado español que rompió con la tradición de buscar el origen bíblico que procede de los "falsos cronicones" fue Gregorio Mayans que redescubrió y publicó en 1742 a quien había sido el primer crítico: el fraile Nicolás Antonio del siglo XVII y su obra inédita Censura de historias fabulosas (PASAMAR 2010, p. 11, 33, 35 y 40). Este ilustrado ha sido profundamente estudiado y recuperado para el conocimiento historiográfico español (MESTRE 1978; 1990; 1999; 2007).

\section{Nativos canarios}

El libro segundo está dedicado íntegramente a las sociedades aborígenes de cada isla, aportando datos históricos y antropológicos, así como políticos de los primeros canarios. Aquí radica su originalidad y la diferencia fundamental con las otras historias de España del siglo XVIII. En las referencias a los guanches aproxima, en muchas ocasiones, la historia a la mitología, aparecen como atlantes, sitúa a esta cultura aborigen próxima al mito de la Edad de Oro dentro del mito de las tres edades, son idealizados, modestos, generosos con honor. Hay una inspiración rousseauniana pero Viera siempre se mostró respetuoso con el dogma católico.

Viera representó un nuevo modo de tratar la historia del Archipiélago y la evolución de su configuración cultural. El aborigen ocupó un lugar central porque era su propio objeto de estudio. Nos muestra la sociedad aborigen idealizada, caracterizada por un primitivismo, donde abandona los principios escépticos y su enfoque racionalista (CASTRO 1996, p. 703-725). Para él, el guanche, viene a encarnar el papel del "buen salvaje" de sus maestros franceses, hacia ellos presenta una actitud comprensiva, mientras que los conquistadores y los misioneros serán el blanco de sus críticas (ESTÉVEZ 1987, p. 71, 73), los considera "afortunados" por ese estado de primitivismo, ingenuidad, naturalidad, sencillez y armonía con la naturaleza que le acercan al prerromanticismo. Realmente Viera aporta poco a sus fuentes ilustradas, insiste que eran de "costumbres simples", "valientes, generosos, fieros y celosos de su libertad natural" con una vida sencilla, defendía su tierra y ensalzaba sus costumbres. Para los ilustrados, ya no quedaban verdaderos salvajes, se habían transformado, aunque de 
sus antiguas enseñanzas podíamos obtener lecciones morales y políticas. En cualquier caso, el "buen salvaje" fue la expresión de la mala conciencia del pensamiento ilustrado del siglo XVIII (ESTÉVEZ 2008, p. 92).

En un contexto similar, el problema del indio americano, la naturaleza del Nuevo Mundo y las consecuencias de las conquistas perpetradas por los españoles se debatieron durante todo el siglo XVIII (GONZÁLEZ 1992, p. 11-40). Muchos misioneros idealizaban al indio, pero también hubo otros que lo describieron con cruel severidad; los jesuitas ponían de relieve aspectos negativos pero esos aspectos eran los que mejor hacían resaltar la firmeza, la paciencia, el espíritu de sacrificio de los buenos padres (GERBI 1982, p. 81). Además, hubo una corriente seguidora de corte rousseauniano que consideraba, como sabemos, al hombre en estado natural como civilizado y al hombre social como corrompido. A partir del Discours sur l'origine et les fondements de l'inégalité de 1754, el mito del noble salvaje fue expandiéndose por Europa dentro de la idea de las poblaciones primitivas.

Los conquistadores son censurados en algunas de sus actitudes por su crueldad mientras que el aborigen es elogiado. El pasado aborigen es concebido en los marcos convencionales tópicos del imaginario pastoril y de la oda heroica, y en un mundo equivalente al de los héroes griegos que no deben ser sometidos a la crítica racional (ARENCIBIA 1996, p. 15). No obstante, Viera escribe siempre como europeo, esa crueldad del conquistador es a veces necesaria, de hecho, siempre habla en primera persona del plural, se reconoce parte de esos castellanos. La entronización de las diversas dinastías insulares aborígenes las pone en relación con las grandes monarquías europeas y la presenta como la consagración del absolutismo, y explica cómo los primeros "reyezuelos" se transformaron en déspotas (CASTRO 1996, p. 584).

También es destacable que, bajo las influencias del interés por la egiptología del siglo XVIII, estableció algunas relaciones entre las momias guanches con las de Egipto, sin base experimental, a pesar de eso, todavía hallamos historiadores canarios que tratan de establecer relaciones de este tipo, amparándose en esas afirmaciones de nuestro ilustrado para sustentar diversas teorías acerca del origen de los primitivos canarios.

\section{Historiografía ilustrada}

En el tomo tercero aparecen las primeras referencias de su autor a problemas económicos de Canarias, reflejando una visión de la Historia como un todo interrelacionado en que los pueblos y los hombres juegan un papel heroico y simultáneamente malvado (BERGASA 2008, p. 25).

La parte dedicada a los siglos del Antiguo Régimen debe mucho a la historia genealógica, dado que los acontecimientos aparecen al hilo de las vidas de los sucesivos señores de las respectivas islas o al del examen del mando desempeñado por las autoridades superiores de las islas realengas (CASTRO 1996, p. 112).

Durante el siglo XVIII habrá cuatro esferas que atraigan la curiosidad historiográfica: la Historia inmediata como memorias y diarios; la Historia de 
Ios Estados por medio de la de sus príncipes; la Historia de Roma, no obstante, el rápido descenso de la redacción en lengua latina de las obras históricas; la Historia exótica, del extremo Oriente y de América como la de los orígenes de los Estados europeos (CARBONELL 1981, p. 101-102). En el caso de la Historia de Canarias nos movemos entre lo exótico del archipiélago y algunas de sus relaciones con América, y, por otro lado, el interés por la inmediatez en algunos capítulos de los 19 libros, inaugurando una historia regional, de las primeras de España, que siguió practicándose en los siglos XIX y XX en toda Europa. Intentó dar una visión de conjunto de Canarias como parte integrante de la historia universal, que confería al Archipiélago un reconocimiento e identidad de pueblo.

Su visión de la Historia está mediatizada por dos aspectos esenciales: la clase social a la que pertenecía y, su propia formación ilustrada.

En España, a partir de comienzos del siglo XVIII, nos encontraremos con una serie de trasformaciones que irán marcando el proceso de secularización de la vida social, política y económica, acelerado en el último tercio de la centuria.

Los Reyes favorecieron una insólita perspectiva de monopolio ideológico en favor de las ideas ilustradas, las cuales fueron forjadas por una minoría y mantenidas entre luz y sombra.

En el siglo de las luces se produce una reacción, que hacía falta, contra la preocupación por la historiografía militar, dinástica y diplomática. Se dio una nueva importancia a los factores culturales e intelectuales, y se atendió a la vida del pueblo y a los hábitos y costumbres de los hombres en las diferentes sociedades, por eso la Historia de Viera y Clavijo no es una mera historia militar y de relaciones internacionales como se había venido haciendo, sino que está a tono con estas ideas ilustradas, con preocupación por la sociedad, la economía, la naturaleza, la salud. Combina, de forma convincente, la erudición con la interpretación.

Tal vez por su condición eclesiástica o por el carácter confesional de la monarquía española, dedica muchas páginas a la historia de la iglesia y de la religión. En los siglos XVI y XVII la mayoría de las obras históricas introducían el vector religioso-eclesiástico (SÁNCHEZ MARCOS 2003, p. 135-136). Durante el siglo XVIII español hallamos historias eclesiásticas como la del ilustrado valenciano Enrique Flores que ponía el énfasis en los aspectos que tocaban a las leyendas piadosas y patrióticas (FLORES 1747-1777).

La Iglesia canaria en estos momentos atraviesa una etapa clave, ya que se encuentra ante la tesitura de elegir entre la tradición y las luces innovadoras. En el contexto de la obra historiográfica de Viera, la Iglesia trató de desarrollar un papel reformista y de avance, con la destacada actuación de tres obispos: Juan Bautista Cervera (1769-1777), Joaquín Herrera de la Bárcena (1779-1783) y Antonio Tavira y Almanzán (1791-1796). Los ilustrados se preocuparon a nivel individual de lo que algunos calificaron "excesiva credulidad del pueblo llano o analfabetismo religioso", así Viera y Clavijo escribió algunas obras sobre asuntos religiosos con afán crítico, bastante avanzado para la época. Otro problema con que se tropezó la Iglesia canaria fue la contextura sociológica que imponía ciertas particularidades, puesto que se trataba de una población heterogénea en 
sus orígenes y que había ido teniendo continuos cruces, bien por asentamientos extranjeros o por contactos comerciales, como la afluencia de población del continente africano, negros y moriscos. Esta particularidad obligaba a una cierta flexibilidad a la hora de aplicar las normas que no se daba en otras áreas del resto de la Corona española.

Todos estos aspectos hoy en día siguen siendo preocupación de la historiografía canaria, ahora por distintos intereses. En el pensamiento ilustrado la Historia es un instrumento para promover la reforma de la sociedad y, al mismo tiempo, la Historia era otro campo a reformar debido a la pasividad mostrada por la Real Academia. Como ha señalado Antonio Mestre, "todo ilustrado era un reformador que buscaba en la historia la solución a las deficiencias de su tiempo" (MESTRE 1990, p. 60). Y Viera se mueve en el mundo reformista del reinado de Carlos III, reformas que querían hacer ver al mundo su especial atención a los asuntos canarios y americanos.

Los conceptos claves de la Ilustración, "razón", "naturaleza" y "cultura", intervienen con una plenitud que parece dirigida a compensar el cúmulo de irracionalidades que caracteriza a su momento histórico.

Hubo una transformación de la idea de progreso a finales del siglo XVIII, estudiada por Koselleck (2012, p. 95-112), paulatinamente, se abandonó la vieja noción de que el mundo envejecía y corrompía inexorablemente, al igual que el cuerpo humano, y se adoptó la idea de que, quizá, el avance de las ciencias y del conocimiento llevaría a la humanidad al completo hacia la prosperidad permanente.

A pesar de ese individualismo radical, la organicidad del orden estamental no desaparece totalmente. El primer cometido que se adscribe a las leyes consiste en la determinación de los oficios, otros tantos vehículos que canalizan las acciones individuales "al bien general", punto de encuentro de la felicidad individual y de la social. De ahí que la sociedad sea vista no sólo como ámbitos de derechos, sino también de deberes recíprocos (ELORZA 1989).

La conciencia política generada con la Ilustración suscitó también un amplio interés por la Historia en toda Europa. Desde 1663 se funda en París la Acedémie des inscriptions et des belles lettres, que se dedicaba al estudio de la Historia y, a imitación de ésta, se fueron fundando otras similares en diversos países a lo largo del siglo XVIII (HOF 1993, p. 52, 94). En Francia vemos un nutrido grupo de historiadores que escriben sobre el pasado bajo las ideas ilustradas. Algo parecido ocurrió en casi todos los países europeos donde había avanzado más la Ilustración con la proliferación fundaciones de Academias (BARRET-KRIEGEL 1998).

El ideal moderno de cultura siempre ha estado asociado con el saber histórico y antropológico. En el plano teórico, toda la historiografía de nuestra época ha estado fuertemente vinculada al proyecto moderno.

Se partía de la premisa de que existe un estado social, político, económico ideal, y todo el pasado constituye el camino en pro de ese fin. La filosofía de la Historia ilustrada trata los aspectos de en qué medida, bajo qué condiciones y hasta qué punto la Historia, en cuanto evolución de la comunidad humana, puede llevar a la realización del bien. 
Por medio de esa concepción del progreso, plantea que para saber si el hombre va a mejor, se debe hacer una Historia profética de los hechos futuros, haciendo esa elaboración a priori de los acontecimientos que van a ocurrir. Esto es posible cuando el historiador-profeta, hace y ejecuta los hechos que anuncia con anticipación (KANT 1987, p. 56), así en su Historia General vemos que Viera cree en la cultura del progreso, mito de la historia.

Viera supera con creces las historias del siglo XVII que ni tan siquiera, ofrecían las fuentes de las que tomaban los datos. Pretendía poner en marcha el proyecto a partir de tres pilares fundamentales: la documentación, la multidisciplinariedad, y la duda metódica (SANTANA 1999).

\section{Fuentes de la Historia de Viera}

Pudo consultar importantes documentos en la Santa Sede, en Roma, especialmente las bulas papales en que se nombraba a Canarias. En una carta que envía a Antonio Porlier desde Viena el 10 de enero de 1781, confiesa entusiasmado que en ese archivo descubrió "muchas bulas originales, y noticias no menos curiosas que ignoradas por lo que han de dar una nueva luz a las antigüedades de aquella Iglesia" (VIERA 1984, p. 61). También pudo obtener información del archivo Secreto de la Catedral de San Ana en la ciudad Las Palmas, lo ordenó y catalogó; halló bulas del siglo XIV, rescriptos papales, cédulas reales, innumerables cartas y documentos, libros de registro y administración, etc. (SÁNCHEZ RODRÍGUEZ 2007, p. 78).

No obstante, las fuentes fundamentales de su libro fueron Le Canarien (que pudo adquirirlo en París), crónica escrita por dos frailes normandos y, por otro lado, la crónica de Abreu Galindo, aunque las somete a un relativo espíritu crítico, propio de los ilustrados. Debemos añadir el conocimiento de la Información de Pérez de Cabitos de 1477 que se conserva en El Escorial. Realmente, copia la historia de los primitivos canarios, pero con algunas aplicaciones de ciertos esquemas y conocimientos propios del siglo XVIII europeo.

Nuestro autor leyó muchos textos que se referían a la historia de Canarias, que ninguno poseía un discurso histórico riguroso. Criticó duramente la obra de Núñez de la Peña $(2008)^{5}$ por la cantidad de imprecisiones, llegó a afirmar que se trataba de un hombre sin demasiada instrucción ni estilo, que le llevó a hacer una "historia insípida, envuelta en muchos arcaísmo, errores y equivocaciones", tal como dice en el prólogo, incluso dedica dos capítulos titulados "Equivocaciones de Núñez de la Peña. ${ }^{6}$ Viera y Clavijo también sacó cinco números de un periódico manuscrito, elaborado íntegramente por él, donde trata de un cargo defensor de los intereses populares, el Síndico Personero, y allí también hace referencia al historiador aludido de forma crítica, dirá "sólo sirven nuestros Personeros para fijar las épocas de nuestra historia o para añadir cada uno un renglón a la estéril

\footnotetext{
5 También sabemos que Viera y Clavijo manejó los trabajos de Núñez de la Peña porque Lope Antonio de la Guerra y Peña se los envió desde Tenerife, conservamos la copia de dicho documento en A.M.C., Colección de Documentos de Agustín Millares Torres, Tomo III, Legajo 3, fls. 22 recto-25 vuelto.

${ }^{6}$ El capítulo XLVIII del libro séptimo y el capítulo XIX del libro octavo.
} 
cronología de D. Juan Núñez de la Peña".7 Algo similar sucede con el poeta Viana (1996) a quien tilda de "falso adalid" (VIERA 2004, p. 2-3), o fray Alonso de Espinosa (1980) de quien dice que tenía la "incertidumbre como fusión". Del mismo modo, sabemos que manejó como fuentes históricas los libros de José de Sosa (1849), Marín y Cubas (1986), Bartolomé García del Castillo (2003) o Pedro Agustín del Castillo (2008), a todo ello le añadió la consulta de los libros de acuerdos del cabildo de Tenerife y reales cédulas.

Más que un detallado trabajo de archivos, hace un trabajo bibliográfico, tuvo siempre un entorno personal en el que los libros y la escritura ocuparon el lugar más relevante (LUXÁN 2007, p. 24). Lo cierto es que pudo consultar los archivos oficiales, así como documentos facilitados por otros ilustrados que hacían de corresponsales en las islas, especialmente otros participantes de la Tertulia de Nava, en La Laguna, que había impulsado la obra. Tomás Lino de Nava-Grimón Porlier coordinaba las informaciones remitidas por una red conformada por José Antonio de la Guerra y Fernando de Molina y Quesada en Tenerife, José Van de Walle en La Palma, Fernando de la Guerra ${ }^{8}$ en Lanzarote y un "amigo anónimo" en Fuerteventura (HERNÁNDEZ 2006, p. 58). Sabemos que también colaboraron otros importantes ilustrados como Lope de la Guerra y Peña, citado en el prólogo del segundo tomo, tenemos constancia que recopiló la historia de las fundaciones de parroquias y conventos de Tenerife que Viera empleó en el tomo IV de su magna obra. ${ }^{9}$

No obstante, hay una ausencia de utilización de fuentes diferentes, no ofrece varias versiones de un acontecimiento determinado, como por ejemplo cuando habla del garoé, el mítico árbol herreño donde se deja llevar por la versión de un testigo.

A su favor podemos señalar que en ocasiones se lleva por el sentido común y la racionalidad propia de la Ilustración, así como una actitud crítica personal que muchas veces coincide con investigaciones posteriores. Crea, interpreta y piensa a partir de unos hechos. Pero, aunque trata de fechar con exactitud, es objetable el desinterés por la cronología entre los acontecimientos que aparecen, por ejemplo, en el capítulo XXVIII del libro octavo en el volumen segundo, introduce la experiencia del británico George Glas en 1764, mientras que el resto de ese libro habla del proceso de conquista en el siglo XV.

Además, obtuvo una licencia para leer libros prohibidos, aunque sufrió diversos problemas relacionados con la Inquisición debido a los peligros de historiar en esa época. Debemos reconocer que algunos de los hechos denunciados por el Santo Oficio canario contienen inexactitudes y no son imparciales, por lo que la Inquisición pretendió que suprimiese algunos párrafos. Las críticas se centran concretamente en las querellas del obispo Rodrigo de Roxas; sabemos que Viera se equivoca (probablemente de forma intencional) sobre la condena

\footnotetext{
7 Archivo de la Biblioteca Municipal de Santa Cruz de Tenerife (B.M.S/C. TFE), Signatura: 11-2-6, tomo VI, Memoriales del Síndico Personero. Memorial I, 20-1-1764, fl. 56 recto. Existe una edición impresa de los 5 números de este periódico editado por NEGRÍN (1994).

${ }^{8}$ El marqués de San Andrés, Fernando de la Guerra, envió información a Viera sobre los condes de La Gomera, como se conserva en A.M.C. Colección de Documentos de Agustín Millares Torres, T. V, Leg. 2, fols. 37 r.-40 r.

${ }_{9}^{9}$ A.M.C. Colección de Documentos de Agustín Millares Torres, Tomo III, Legajo 10, fls. 77 r-112 v.
} 
final en la versión ofrecida en esta Historia acerca del proceso inquisitorial y la sentencia de Cristóbal del Hoyo Solórzano, marqués de San Andrés y vizconde de Buen Paso, dado que el marqués nunca fue absuelto, ni los inquisidores se excusaron; los inquisidores también atacaron algunas fuentes utilizadas por Viera, como la Semi-historia del padre Mathías Sánchez (2008) y el Informe instructivo del arcediano José Marcos Verdugo y Alviturría.

Sin embargo, las solicitudes del Santo Oficio de Canarias para que se expurgase la obra de Viera obtuvieron por respuesta un lacónico "enterado" y que se tomarían las medidas oportunas; la Suprema ordenó que fueran enviadas al tribunal de la Corte una copia del libro para que fuera calificado y censurado, pero el tribunal madrileño incumplió la petición. De cualquier modo, podemos observar que las quejas no se dirigen al liberalismo de la interpretación histórica, sino únicamente tienen que ver con las aspectos que desprestigiaban al Santo Oficio con la ironía de Viera, máxime teniendo en cuenta que la primera carta de la Inquisición de Canarias a la Suprema acerca de la Historia de Viera y Clavijo está fechada el 18 de septiembre de 1784, y la segunda misiva fue del 7 de febrero de 1792, es decir, en una coyuntura de ataques al Tribunal de la Fe (ANAYA 1997, p. 173-182). ${ }^{10}$ Los inquisidores buscaban el momento de intervenir contra los menos ortodoxos, pero eran conscientes de que su contraataque rozaría las fronteras del obispado, por ello se limitaron a mandar informes al Consejo Supremo.

Probablemente debido al miedo al proceso revolucionario que se vivía en Francia, en 1791 las clases de Historia fueron suspendidas, y el 24 de febrero se ordenó la suspensión de todas las publicaciones privadas españolas quedando sólo la prensa oficial. Es decir, que se restringió la libertad de pensamiento y se actuó contra los exponentes de la Ilustración.

\section{Filosofía de Viera}

En el prólogo al primer tomo a pesar de reconocer que pretende "promover los verdaderos intereses de las Canarias", afirma que pretende ser una pluma "hábil e imparcial", pero los historiadores no pueden ni deben tener una capacidad imparcial, puesto que no podemos ser neutrales, sino que el producto historiográfico depende del interlocutor que nos cuenta la Historia. Diferenciamos completamente la imparcialidad de la objetividad, no podemos ni debemos ser imparciales, eso podría ser éticamente reprochable, siempre tomamos partido por unos o por otros, en nuestro caso por los más desfavorecidos, pero sí debemos ser objetivos en seguir una metodología y el respeto absoluto a las fuentes. Por tanto, es inaceptable la idea posmoderna ampliamente extendida qué mantiene que no existe la verdad histórica, sino distintas versiones de la historia, todas ellas iguales de legítimas. Creemos que el dato histórico ocurrido fue objetivo y nos aproximamos más o menos en función de la metodología utilizada y las fuentes.

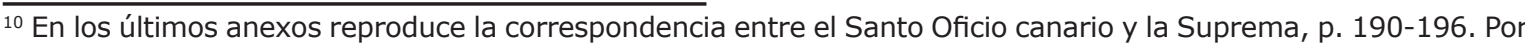
otra parte, DOMERGUE (1984) recoge los libros autorizados y prohibidos por la censura. Examina la forma en que el Santo Oficio dirige la lucha contrarrevolucionaria en el dominio ideológico. En concreto para Canarias tenemos el trabajo de DÍAZ (1989-1990, p. 67-72)
} 
Viera y Clavijo se educó en la filosofía escolástica, pero pronto la desechó. Pensaba que todo debía ser transparente a la razón y, nada debía ser aceptado de forma acrítica, es decir, que todo lo que se cree cierto, pudiera no serlo. Hizo carrera eclesiástica y al mismo tiempo, fue influido por la doctrina racionalista. Se dedicó a la historia con constancia, superando sus limitaciones.

En el pensamiento ilustrado tuvo un importante peso el pirronismo histórico, es decir, no creer con ligereza y saber dudar en muchas ocasiones, fruto de haber extendido la reflexión crítica al terreno de la historia, que no limitaba la discusión de la validez de las fuentes, sino que la aplicaba a los contenidos, hechos, ideas, valoraciones (FONTANA 1982, p. 62).

Podemos apreciar una doble influencia de Montaigne y Descartes, en Viera, escepticismo unido a fe ciega en las verdades personalmente comprobadas por el método silogístico. Aplica la crítica a la sociedad en que vive, la experiencia a la ciencia y el sentido común a la historia (CIORANESCU 1982, p. XXII; 1977, p. 188). La Historia le interesa como comprensión de la sociedad en la que vive, la que explica los progresos de la sociedad europea, desprecia la erudición y se acerca al hombre como sujeto de la sociedad. Viera no se basó únicamente en aspectos filosóficos, sino también sobre temas centrados en la vida cotidiana. La Historia occidental, la sucesión de los pueblos judío, griego y romano, envueltos por los bárbaros, es estimada, por tanto, como una de las posibles y no la única. Además, piensa que la historia debe servir para formar súbditos y proveer de modelos y ejemplos para el presente, por eso enjuicia y moraliza los acontecimientos que pertenecen a un pasado ajeno.

Muchas veces ha sido comparado con Voltaire, quizás nos parece excesivo, pero lo cierto es que pudo leerlo en la biblioteca de los marqueses de Villanueva del Prado y según afirmó el obispo Verdugo fue traductor suyo. En cuanto a la labor historiográfica, Voltaire trata de superar el marco de la historia política tradicional para construir la del espíritu humano. Situó a la Razón en el centro del pensamiento y además de teorizar sobre la historia, escribió varias obras propiamente historiográficas: El siglo de Luis XIV, Historia del Imperio Ruso bajo el reinado de Pedro el Grande y Ensayo sobre las costumbres y el espíritu de las naciones.

Viera ha sido considerado un personaje afrancesado volteriano, si no llegó a tanto, al menos hay que reconocerle su formación enciclopédica. Y sí que es cierto que mostró un interés preferente por la historia que estaban haciendo los franceses. Viera al igual que Voltaire dio importancia a los acontecimientos diplomáticos y militares, y en ambos casos hay una preocupación por perseguir documentos inéditos.

También la historiografía británica del siglo XVIII vio en el desarrollo histórico como una historia de la civilización. El análisis de cada época y de la evolución de cada pueblo, aparece en el contexto global del progreso hacia el conocimiento racional. Aquí destacaron especialmente David Hume, William Robertson y Edward Gibbon (SÁNCHEZ MARCOS 1988, p. 230-240), que probablemente fueron conocidos por Viera. 


\section{Nueva forma de hacer Historia}

Desde el punto de vista historiográfico es destacable la interpolación de material antropológico, histórico y cultural, donde expone contactos entre culturas diferentes en unas condiciones específicas, con una preocupación por el estudio de los grupos y etnias, sus creencias, sus instituciones y el funcionamiento de sus sociedades. También percibimos un creciente interés por el mundo vegetal y animal.

No tienen una intención deliberada de engañar distorsionando la realidad, pero presenta algunos fragmentos como reales, que, en verdad, responden a hechos imaginarios que él mismo creía que eran ciertos, de este modo, incluye algunos mitos y leyendas cuando falla la documentación. ${ }^{11}$

Tenemos varios ejemplos de la incorporación de estas historias fantásticas, que no tienen soporte en acontecimientos reales, une mitología e historia como el relato del príncipe Hércules, la muerte de Guillén Peraza o el cuento de Dácil y sus amores con Gonzalo García del Castillo que carecen de autenticidad, únicamente se basan en los amores cantados por el poeta Viana que los acepta como reales en su preocupación por la anécdota. La ficción toma protagonismo cuando presenta un suceso que es fabuloso como si fuese cierto (GALVÁN 1999). ${ }^{12}$

Presenta una cuidada redacción y un estilo literario destacado a la hora de escribir su Historia, sin renunciar a la dramatización, aunque desde la Inquisición se le critica acusándolo de galicista, de falta de rigor y de escaso ingenio, pero creemos que fue más motivado por un enfrentamiento corporativo que un hecho constatado. Su calidad literaria es innegable, con una prosa culta obtiene un texto ligero y ameno, pero ello no menoscaba su historicidad.

Antonio M. Bernal (1988) fue el primero que relacionó la obra de Viera con las crónicas americanas, pero creemos que es mayor el peso de los ilustrados franceses que de Bartolomé de Las Casas (1977) quien había publicado en 1552 en Sevilla toda una serie de tratados provocativos y la Brevísima Relación de la Destrucción de las Indias. Lo cierto es que es innegable esa relación con las crónicas indianas en las descripciones de obispos y generales, lejos de la tradición historiográfica del siglo XVIII, aunque con cierta distancia de las crónicas europeas anteriores de reyes y príncipes. Hay historias semejantes a las de grandes héroes en América, que denotan una relación con las gestas de los conquistadores en aquel continente. Igualmente, las comparaciones entre costumbres aborígenes con héroes de la épica griega.

Igualmente debemos destacar que su método crítico le lleva a dudar de cualquier autoridad y a realizar análisis de las fuentes. Antonio de Bethèncourt afirma que Viera conocía las técnicas de los documentalistas del siglo XVII de la escuela de Masillon, valoró la técnica sobre el análisis del contenido del documento, sin caer en el fetichismo de ese documento (BETHĖNCOURT 1991, p. 29).

${ }^{11}$ Vemos muchas de esas leyendas referidas a los primitivos canarios, contamos con una recopilación de todos esos mitos (GARCÍA Y GARCÍA DE LA TORRE 1969).

12 Esta es la publicación más extensa y más desarrollada de la obra historiográfica de Viera y el libro en su conjunto es, sin duda, el trabajo más riguroso hasta la fecha. 
También escribió algunas obras en versos en las que, sin intentar ser un tratado de historia, narran hechos pasados, y en ellas hay una visión implícita de la historia porque recurre a un suceso real y creíble, aunque suele mezclar la realidad con la ficción. En estos casos es aun, mayor el alejamiento de la realidad en esa poética histórica. Tomó inspiración en hechos históricos buscando gestas nacionales como la de Hernán Cortés o la toma de Granada por los Reyes Católicos en 1492.13 De este segundo hecho elaboró un romance heroico que presentó a un concurso poético convocado por la Real Academia de la Lengua Española en 1779. Se trata de un largo poema donde relata de forma superlativa la última batalla entre los andalucíes y los cristianos del norte (VIERA 2009, p. 38-54).14

En esta misma línea también cabe destacar El segundo agatocles o Cortés en la Nueva España, escrita también con motivo del concurso literario convocado por la Real Academia en 1778, para premiar el mejor poema épico sobre la figura de Hernán Cortés. Viera y Clavijo lo envió desde París, pero no fue galardonado. Este poema ha sido objeto de un estudio monográfico por parte de Victoria Galván (1991). El personaje central, el representante de la Corona castellana, no aparece inserto en su época, sino en el siglo XVIII, por tanto, favorable a Carlos V y su sucesor ahora, Carlos III. Además, Cortés está mitificado en su gesta por convertir infieles al cristianismo:

Recibiónos el jefe muy gozoso.

Es su nombre Cortés y que discreto

Bajo de un velo afable y majestuoso

Supo ocultar un corazón inquieto. ${ }^{15}$

El poema también centra su interés en los aborígenes, en este caso mexicanos, convirtiendo a Moctezuma en el segundo protagonista de la épica; no aparece como un gran rey, las costumbres indígenas son bárbaras con una religión cruel debido a que la fuente que utiliza son las crónicas de Hernán Cortés.

A su currículo como historiador debemos añadir que Viera y Clavijo fue miembro de la Academia de la Historia, primero como correspondiente y más tarde como supernumerario, recibiendo la medalla de oro. En su Oración gratulatoria de ingreso en la Real Academia de la Historia, manifestó su satisfacción por "estar escrito en la lista de aquellos hombres útiles, destinados a publicar las hazañas, grandezas, antigüedades y virtudes de la Nación", y llamó la atención sobre la falta de historiadores hispanos dejando el campo a extranjeros, junto con la necesidad de hacer una historia española de acuerdo a las nuevas concepciones investigadoras y metodológicas (MARTÍNEZ 1982, p. 34). ${ }^{16}$ También hizo de censor en diversas ocasiones, como parte de su actividad en esta institución. Justamente estuvo vinculado a la Academia de la Historia

\footnotetext{
${ }_{13}$ A.B.S/C.TFE, Sig: ms. 28 (2), manuscrito autógrafo, foliado a lápiz 24-39.

${ }^{14}$ La introducción (GALVÁN 2009, p. 12) hace referencia a esta poesía épico-heroica y patriótica así como a otros poemas que recrean acontecimientos de la historia local.

15 A.M.C. Fondo de Juan Padilla, Manuscritos, Volumen I, José Viera y Clavijo: Poesías, 1876, p. 9.

${ }^{16}$ El texto original de esta obra se conserva en A.R.S.E.A.P.TFE., Fondo Rodríguez Moure, Sig: 10/376, con edición de Las Palmas de Gran Canaria: Real Sociedad Económica de Amigos del País de Gran Canaria, 1807.
} 
en los años que andaba con el cuarto tomo, es decir, fines de los setenta y principios de los ochenta.

Además, en su trabajo como ayo del hijo del marqués de Santa Cruz se vio obligado a preparar un opúsculo de Historia, como Epítome de la Historia Romana, de la Historia de España y de la Historia eclesiástica, sin embargo, no podemos extraer ninguna información de esa obra dado que se puede considerar perdida (BLANCO 1981, p. 26).

Igualmente mantuvo actividades como documentalista, fue compilador de las actas de la Real Sociedad Económica de Amigos del País de Las Palmas desde su creación en 1777 hasta 1799, realizó el extracto de las actas del cabildo catedral de Canarias, recopilando toda la información desde 1514 a $1790^{17}$ y en 1793 fue nombrado por el Comandante General Antonio Gutiérrez, revisor real de los libros e impresos extranjeros que llegasen a la Aduana de Canarias (HORMIGA 2006, p. 34).

\section{Conclusiones}

La obra historiográfica de Viera y Clavijo fue la primera visión de conjunto de toda la Historia de Canarias en concordancia con las ideas ilustradas, que sin ser la más vanguardista en Europa, ni en España, sí que supuso un enorme paso adelante en el pensamiento canario. A pesar del poco reconocimiento alcanzado en su momento por su Historia General, tal como pronosticaba su coetáneo ilustrado Tomás de Nava-Gimón en una carta que le envía el 30 de agosto de 1772: "Aunque es cierto que este trabajo y gasto, será poco reconocido de pronto en nuestra Patria, también lo es que servirá para inmortalizar en ella el nombre de Vmd. Y hacerlo amable en el futuro".18

Sin duda alguna, Viera y Clavijo es el historiador más representativo de la Ilustración canaria y el más conocido de todos los tiempos. Existe una amplia bibliografía sobre sus obras, hemos podido localizar 182 trabajos de mayor o menor extensión, dedicados a este autor de forma monográfica, ${ }^{19}$ incluso hemos hallado alguno más.

La identidad canaria hoy en día es deudora de la obra de Viera y Clavijo, muchos de sus mitos e imaginarios arrancan de su Historia y, continúa moviéndose en esos cánones de la Ilustración canaria dieciochesca.

\footnotetext{
17 A.M.C. Extracto de las actas del Cabildo de la Diócesis de Canarias, 1514-1790, Por José de Viera y Clavijo, Copia de Agustín Millares Torres

${ }_{18}$ Cartas de Don Tomás Lino de Nava-Grimón Porlier, V marqués de Villanueva del Prado, desde La Laguna, a Don Joseph de Viera y Clavijo en Madrid. Transcripción, estudio preliminar y notas de Enrique Romeo Palazuelo, La Laguna: Instituto de Estudios Canarias, 1988, p. 44.

${ }^{19}$ Contamos con una muy buena recopilación en la base de datos bibliográfica de Canarias y el Atlántico dirigida por Antonio de Bethèncourt Massieu: www.canaratantico.org. En total suman 210 pero incluye las obras del propio José de Viera y Clavijo, algunos son trabajos periodísticos, pero otros son importantes estudios muy completos.
} 


\section{Referencias bibliográficas}

ÁLVAREZ MARTÍ-AGUILAR, Manuel. La Antigüedad en la historiografía española del siglo XVIII: el marqués de Valdeflores. Málaga: Universidad de Málaga, 1996.

ANAYA HERNÁNDEZ, Luis Alberto. Los problemas de Don Josef Viera y Clavijo con la iglesia y la inquisición canaria Anuario de Estudios Atlánticos, n. 43, p. 165-196, 1997.

ARENCIBIA, Yolanda. Tradición, Historia y Literatura: de Viera y Clavijo a Pérez Galdós. Las Palmas de Gran Canaria: Universidad de Las Palmas de Gran Canaria, Conferencia Inaugural del curso académico 1995-96, 1996.

ARIAS MARÍN DE CUBAS, Tomás. Historia de las siete islas de Canaria. Las Palmas de Gran Canaria: Real Sociedad Económica de Amigos del País de Gran Canaria, 1986.

BARRET-KRIEGEL, Blandine. La Défaite de I'érudition. Paris: PUF, 1998.

BERGASA PERDOMO, Óscar. José de Viera y Clavijo (1731-1813). La economía de su tiempo. Sus ideas y sus obras. Las Palmas de Gran Canaria: Real Sociedad Económica de Amigos del País de Gran Canaria, 2008.

BERNAL, Antonio M. Canarias y su historia: la obra singular de Viera y Clavijo. In: Serta Gratulatoria in honores Juan Régulo. La Laguna: Universidad de La Laguna, 1988. t. III, p. 257-265.

BETHENCOURT MASSIEU, Antonio de. Introducción. In: VIERA Y CLAVIJO, José de. Historia de Canarias. Islas Canarias: Gobierno de Canarias, 1991.

BLANCO MONTESDEOCA, Joaquín. Biografía de José de Viera y Clavijo. In: VIERA Y CLAVIJO, José de. Extracto de las actas de la Real Sociedad Económica de Amigos del País de Las Palmas (1777-1790). Las Palmas de Gran Canaria: Real Sociedad Económica de Amigos del País de Las Palmas, 1981.

CARBONELL, Charles-Olivier. L'historiographie. Paris: Presses Universitaires de France, 1981.

CASTRO ALFÍN, Demetrio. Viera y Clavijo y su historia. La continuidad de un género. In LAFORET, Juan José (Ed.). Estudios de historiografía regional. Jornadas en homenaje a Agustín Millares Torres. Las Palmas de Gran Canaria, Real Sociedad Económica de Amigos del País de Gran Canaria, 1996, p. 99-121.

CASTRO ALFÍN, Demetrio. Una vida sencilla y filosófica. El primitivismo idealizado en la Historia de Viera y Clavijo. In: Coloquio de Historia CanarioAmericana, XI. 1994. Las Palmas de Gran Canaria: Cabildo Insular de Gran Canaria, 1996. t. II, p. 703-725.

CASTRO ALFÍN, Demetrio. La historia imaginada, Viera y Clavijo, la 
monarquía y el pasado prehispánico de Canarias in Sociedad Española de Estudios del siglo XVIII. El mundo hispánico en el siglo de las luces. Madrid: Complutense, 1996. t. I, p. 575-585.

CEBRIÁN, José. Del epistolario de Viera y Clavijo y sus amigos de Viena. In: ÁLVAREZ BARRIENTOS, Joaquín; CHECA BELTRÁN, José (Ed.). El siglo que Ilaman Ilustrado. Madrid: Consejo Superior de Investigaciones Científicas, 1996, p. 209-220.

DEL CASTILLO, Pedro Agustín. Descripción histórica y geográphica de las Islas Canarias. Santa María de Guía: Disliber Santa María, 2008.

DÍAZ MARTÍN, Matías. Libros prohibidos en la Biblioteca del Seminario Conciliar de Canarias. Siglo XVIII. Parabiblos - Cuadernos de Biblioteconomía y Documentación, n. 3-4 p. 67-72, 1989-1990.

DOMERGUE, Lucienne. Le livre en Espagne au temps de la Révolution française. Lyon: Presses Universitaires de Lyon, 1984.

ELORZA, Antonio. El temido árbol de la libertad. In: AYMES, Jean-René (Ed.). España y la Revolución francesa. Barcelona: Crítica, 1989, p. 69-117.

ESPINOSA, Alonso de. Historia de Nuestra Señora de Candelaria. Santa Cruz de Tenerife: Goya, 1980.

ESTÉVEZ GONZÁLEZ, Fernando. Indigenismo, raza y evolución. EI pensamiento antropológico canario (1750-1900). Santa Cruz de Tenerife: Cabildo de Tenerife, 1987.

ESTÉVEZ GONZÁLEZ, Fernando. La invención del guanche. Clasificaciones imperiales y correlatos identitarios de la raciología en Canarias. In Fundación Canaria Orotava de Historia de la Ciencia (Ed.). Ciencia y cultura de Rousseau a Darwin. Canarias: Gobierno de Canarias, 2008.

FAJARDO SPÍNOLA, Francisco. Viera y Clavijo, historiador de Canarias. In GALVÁN GONZÁLEZ, Victoria. Viera al trasluz. Idea: Santa Cruz de Tenerife, 2009, p. 85-112.

GERBI, Antonello. La disputa del Nuevo Mundo. Historia de una polémica 1750-1900. México: Fondo de Cultura Económica, 1982.

FLORES, Enrique. España sagrada. Theatro geográfico histórico de la iglesia de España. Madrid: Antonio Martín, 1747-1777. 51 v.

FONTANA, Joseph. Historia. Análisis del pasado y proyecto social. Barcelona: Crítica, 1982.

GALVÁN GONZÁLEZ, Victoria. América en la obra de Viera y Clavijo: El segundo agatocles o Cortés en la Nueva España. In: Homenaje al profesor Sebastián de la Nuez. La Laguna: Universidad de La Laguna, 1991, p. 135-143.

GALVÁN GONZÁLEZ, Victoria. Los diarios de viaje de José de Viera y Clavijo 
(1731-1813). In: SOCIEDAD ESPAÑOLA DE ESTUDIOS DEL SIGLO XVIII. El mundo hispánico en el siglo de las luces. Madrid: Complutense, 1996. t. I, p. 655-668.

GALVÁN GONZÁLEZ, Victoria. La obra literaria de José de Viera y Clavijo. Las Palmas de Gran Canaria: Cabildo Insular de Gran Canaria, 1999.

GALVÁN GONZÁLEZ, Victoria. La ilustración en Canarias. In: ARENCIBIA, Yolanda; GALVÁN GONZÁLEZ, Victoria. Viera y Clavijo bajo el signo de la Ilustración. Las Palmas de Gran Canaria: Cabildo de Gran Canaria, 2013, p. 23-36.

GARCÍA DEL CASTILLO, Bartolomé. Antigüedades y ordenanzas de la isla de El Hierro. Las Palmas de Gran Canaria: El Museo Canario-Cabildo de El Hierro, 2003.

GARCÍA Y GARCÍA DE LA TORRE, José Manuel. Leyendas guanches de las Islas Canarias. Barcelona: Artes Gráficas, 1969.

GONZÁLEZ MONTERO DE ESPINOSA, Marisa. La ilustración y el hombre americano. Descripciones etnológicas de la expedición de Malaspina. Madrid: Consejo Superior de Investigaciones Científicas. 1992.

HERNÁNDEZ GUTIÉRREZ, Sebastián. Josephus Viera y Clavijo, presbyter canariensis. Santa Cruz de Tenerife: Gobierno de Canarias-Ayuntamiento de los Realejos, 2006.

HOF, Ulrich Im. La Europa de la Ilustración. Crítica: Barcelona, 1993.

HORMIGA, Félix. Noticias de José de Viera y Clavijo. Canarias: Gobierno de Canarias, 2006.

KANT, Immanuel. Rencensiones sobre la obra de Herder "Ideas para una Filosofía de la Historia de la Humanidad. In: KANT, Immanuel. Ideas para una historia universal en la clave cosmopolita y otros escritos sobre Filosofía de la Historia. Madrid: Tecnos, 1987.

LAFORET, Juan José. Orígenes de la imprenta en la provincia de Las Palmas. Las Palmas de Gran Canaria: Asociación de Empresarios de la Imprenta y Artes Gráficas de la provincia de Las Palmas, 1991.

LAS CASAS, Bartolomé de. Brevísima Relación de la Destrucción de las Indias. Madrid: Fundación Universitaria Española, 1977.

LUXAN Y MELÉNDEZ, Santiago de. Ensayo de una biblioteca ilustrada. La librería virtual de Viera y Clavijo. Las Palmas de Gran Canaria: Real Sociedad Económica de Amigos del País de Gran Canaria, 2007.

MARTÍNEZ SÁNCHEZ, Juan José. La historiografía en tiempos de Viera. In: VIERA Y CLAVIJO, Joseph de. Librito de la doctrina rural, para que se aficionen los jóvenes al estudio de la agricultura propia del hombre. Santa Cruz de Tenerife: Nicolás González Lemus, 1982, p. 21-35.

MASDEU, Juan Francisco. Historia crítica de España y de la cultura 
española en todo género. Madrid: Don Antonio de Sancha, 1783-1805. $20 \mathrm{v}$.

MESTRE, Antonio. El mundo intelectual de Mayans. Artes Gráficas Soler: Valencia, 1978.

MESTRE, Antonio. Mayans y la España de la Ilustración. Espasa-Calpe: Madrid, 1990.

MESTRE, Antonio. La historiografía española en el siglo XVIII. In: Coloquio Internacional Carlos III y su siglo. Madrid: Universidad Complutense, 1990, p. 21-60. v. I.

MESTRE, Antonio. Don Gregorio Mayans y Siscar, entre la erudición y la política. Alfons el Magnanim: Valencia, 1999.

MESTRE, Antonio. Mayans y Siscar y el pensamiento ilustrado español contra el absolutismo. Universidad de León: León, 2007.

MOHEDANO, Rafael; RODRÍGUEZ, Pedro. Historia literaria de España, desde su primera población hasta nuestros días. Madrid: Imprenta de Francisco Xavier García, 1766-1791. 12 v.

NEGRÍN FAJARDO, Olegario. José Viera y Clavijo: El Síndico Personero general. Obra patriótica escrita periódicamente en la ciudad de La Laguna. Las Palmas de Gran Canaria: Cabildo Insular de Gran Canaria, 1994.

NÚÑEZ DE LA PEÑA, Juan. Conquistas y antigüedades de las islas de la Gran Canaria y su descripción, con muchas advertencias de sus privilegios, conquistadores, pobladores y otras particularidades en la muy poderosa isla de Thenerife. La Coruña: Orbigo, 2008.

PALENZUELA BORGES, Nilo. Viera y Clavijo, entre las dos orillas. El Día, p. 33, 27 dec. 1981.

PASAMAR, Gonzalo. Apologia and Criticism. Historianas and the History of Spain, 1500-2000. Peter Lang: Oxford, 2010.

RÉGULO PÉREZ, Juan. La historiografía canaria después de Viera y Clavijo. In: NUEZ CABALLERO, Sebastián de la. Noticias de la historia de Canarias. Cupsa: Madrid, 1981. v. III, p. 90.

ROMEU PALAZUELO, Enrique. Biografía de Viera y Clavijo a través de sus obras. Santa Cruz de Tenerife: Cabildo Insular de Tenerife, 1981.

SÁNCHEZ, Mathías. Semi-historia de las Fundaciones, Residencias, o Colegios que tiene la Compañía de Jesús en las Islas Canarias. La Laguna, Instituto de Estudios Canarios, 2008.

SÁNCHEZ MARCOS, Fernando. Invitación a la Historia. De Heródoto a Voltaire. Barcelona: PPU, 1988.

SÁNCHEZ MARCOS, Fernando. La historiografía sobre la Edad Moderna. In: ANDRÉS-GALLEGO, José (Ed.). Historia de la historiografía española. 
Madrid: Encuentro Ediciones, 2003, p. 135-136.

SÁNCHEZ RODFRÍGUEZ, Julio. José de Viera y Clavijo. Sacerdote y Arcediano. Las Palmas de Gran Canaria: JSP, 2007.

SANTANA PÉREZ, Juan Manuel. Historiografía canaria sobre el Antiguo Régimen. Almogaren, v. XXX, p. 117-130.

SOSA, José de. Topografía de la isla afortunada Gran Canaria cabeza del partido de toda la provincia comprensiva de las siete islas llamadas vulgarmente afortunadas. Su antiguedad, conquista é invasiones; sus puertos, playas, murallas y castillos; con cierta relación de sus defensas / escrita en la M.N. y muy leal ciudad Real de Las Palmas, por un hijo suyo el M.R.P. Fr. José de Sosa. Santa Cruz de Tenerife: Imprenta Isleña, 1849.

VIANA Antonio de. Antigüedades de las islas Afortunadas. La Laguna: Ayuntamiento San Cristóbal de La Laguna, 1996.

VIERA Y CLAVIJO, José de. Cartas de Don José de Viera y Clavijo a diversas personalidades. Santa Cruz de Tenerife: Goya, 1984.

VIERA Y CLAVIJO, Joseph de. Noticias de la Historia General de las Islas Canarias. Canarias: Gobierno de Canarias, 2004.

VIERA Y CLAVIJO, José. Antología poética. Santa Cruz de Tenerife: Idea, 2009.

VOLTAIRE. El siglo de Luis XIV. México: Fondo de Cultura Económica, 1978.

WULFF Fernando. Las esencias patrias. Historiografía e Historia Antigua en la construcción de la identidad española (siglos XVI-XX). Barcelona: Crítica, 2003. 